Correspondence

Sujoy K. Das Gupta

sujoy@boseinst.ernet.in

Received 7 June 2006

Revised 16 September 2006

Accepted 21 September 2006

\section{The dimeric repressor SoxR binds cooperatively to the promoter(s) regulating expression of the sulfur oxidation (sox) operon of Pseudaminobacter salicylatoxidans KCT001}

\author{
Sukhendu Mandal, Sujoy Chatterjee, Bomba Dam, Pradosh Roy† \\ and Sujoy K. Das Gupta \\ Department of Microbiology, Bose Institute, P-1/12, CIT Scheme VII-M, Kolkata-700 054, India
}

\begin{abstract}
Sulfur oxidation in Pseudaminobacter salicylatoxidans KCT001 is rendered by the combined action of several enzymes encoded by a thiosulfate-inducible sox operon. In this study it has been conclusively demonstrated by insertional mutagenesis that the regulatory gene of this operon is soxR, which encodes a DNA-binding protein belonging to the ArsR-SmtB family. SoxR was found to bind to two promoter-operator segments within the sox cluster, of which the one $(w x)$ located between soxW and sox $X$ controls the expression of sulfur-oxidation genes sox $X$ through soxD while the other, a bi-directional element (sv) located between soxS and soxV, controls the expression of soxVW in one direction and the putative regulatory cluster soxSRT in the other. In the case of the $w x$ promoter the repressor was found to bind in a cooperative manner to two distinct binding sites having different affinities, while in the case of the $s v$ promoter binding occurred at a symmetric dimeric site and involved a higher degree of cooperativity. The high degree of cooperativity observed in the binding of SoxR to its target sites seemed to be due to the propensity of SoxR monomers to form dimers. The apparent dissociation constants of the SoxR-operator complexes were in the nanomolar range, indicating relatively strong interactions. It was demonstrated using a reporter system in Escherichia coli that this high-affinity binding of SoxR led to efficient repression in trans. Thus the role of SoxR as a repressor of the sox operon has not only been conclusively established but it has also been shown that this repression is brought about through cooperative interactions of SoxR with dimeric binding sites that occlude the operon promoters.
\end{abstract}

\section{INTRODUCTION}

Reducing equivalents produced during the oxidation of sulfur compounds are used by chemolitho-autotrophic bacteria for aerobic respiration as well as carbon dioxide fixation, while anaerobic phototrophic bacteria utilize them primarily for carbon dioxide fixation. Thiosulfate, the only sulfur substrate that is universally oxidized by the majority of known chemolithotrophic organisms irrespective of their taxonomic identity, is oxidized directly to sulfate by the $\alpha$ proteobacteria without the formation of any detectable intermediate sulfur compounds in the medium (Kelly, 1989). Genetic studies with both chemo- and photolithotrophic sulfur-oxidizing $\alpha$-proteobacteria like Paracoccus pantotrophus, Pseudaminobacter salicylatoxidans KCT001 and Rhodovulum sulfidophilum have recently led to the identification of a cluster of sulfur oxidation (sox) genes, viz. soxVW and soxXYZABCDEFGH (Friedrich et al., 2000; Mukhopadhyaya et al., 2000; Rother et al., 2001; AppiaAyme \& Berks, 2002). A consensus mechanism allegedly governing the complete oxidation of thiosulfate, sulfite, sulfide and elemental sulfur has been proposed with $\alpha$-proteobacteria as model systems involving a sulfuroxidizing multi-enzyme complex comprising the thiosulfate-induced periplasmic proteins SoxXA, SoxYZ, SoxB and SoxCD (Friedrich, 1998; Friedrich et al., 2001; Appia-Ayme et al., 2001). While the proteins SoxV and SoxW are believed to be involved in the biosynthesis or maintenance of the multienzyme complex system (Bardischewsky \& Friedrich, 2001; Appia-Ayme \& Berks, 2002), the genes soxEFGH, though co-expressed with the sox structural genes in $P$. pantotrophus, might not be essential for sulfur oxidation by the aforesaid mechanism (Rother et al., 2001).

Although some information is available regarding the function of the sox structural genes, there is still insufficient 
knowledge about the regulation of their expression. While mutational and physiological studies with Pseudaminobacter salicylatoxidans KCT001 had previously indicated that the gene cluster soxSRT could be associated with the regulation of this operon (Lahiri et al., 2006), insertional mutagenesis of soxS of Paracoccus pantotrophus resulted in low levels of constitutive expression of sox genes (Rother et al., 2005). This low-level constitutive expression in soxS-inactivated mutants was however attributed to a polar effect on soxR, as the mutant phenotype could be suppressed by the introduction of a plasmid carrying a DNA fragment corresponding to soxR. Although these observations suggested a possible role for SoxR as a repressor, it is still necessary to obtain more direct evidence by inactivating soxR itself and investigating the resulting phenotype. Moreover, although the ability of the SoxR to bind with DNA sequences had been demonstrated earlier, no detailed analysis of binding isotherms and/or delineation of binding sites had been performed.

Previous theoretical investigations by our laboratory with the SoxR of Pseudaminobacter salicylatoxidans KCT001, the model organism of the present study, had revealed that the protein was capable of binding as a dimer to regulatory regions within the sox cluster (Bagchi et al., 2005). The general lack of detailed knowledge regarding the repressor function of SoxR and the availability of a hypothetical model for the binding of P. salicylatoxidans KCT001 SoxR to its target site motivated us to express SoxR of this organism in Escherichia coli and use the purified protein to study its DNA-binding activities. The present investigation not only provides conclusive evidence for the repressor function of SoxR but also offers new insights into the understanding of the binding sites as well as the mechanism of binding of SoxR to different regions within the sox locus (Fig. 1).

\section{METHODS}

Bacterial strains, plasmids and growth conditions. The bacterial strains and plasmids used in this study and their sources are listed in Table 1. E. coli XL-1 Blue (Bullock et al., 1987) or TOP10 was used for cloning experiments, expression work and promoter assays. For promoter assays a $\beta$-galactosidase-based reporter plasmid (pSD5B) was used (Jain et al., 1997). Originally, the vector was constructed for studying mycobacterial promoters. However, pSD5B is equally effective as a promoter-probe vector for E. coli.
Luria-Bertani broth (LB) and Luria-Bertani agar (LA) media respectively were used for growing and maintaining strains of $E$. coli (at $37^{\circ} \mathrm{C}$ ) as well as Pseudaminobacter salicylatoxidans strain KCT001 (Mukhopadhyaya et al., 2000; Deb et al., 2004) and its mutant (at $30^{\circ} \mathrm{C}$ ). E. coli TOP10 used in experiments involving arabinose regulator expression was grown in $\mathrm{RM}$ medium $(\mathrm{pH}$ 7.4) containing $\mathrm{M} 9$ salts $\left(\mathrm{Na}_{2} \mathrm{HPO}_{4} 6 \mathrm{~g}, \mathrm{KH}_{2} \mathrm{PO}_{4} 3 \mathrm{~g}, \mathrm{NaCl} 0.5 \mathrm{~g}\right.$ and $\mathrm{NH}_{4} \mathrm{Cl} 1 \mathrm{~g}$ per litre water), $2 \%(\mathrm{w} / \mathrm{v})$ Casamino acids and $1 \mathrm{mM} \mathrm{MgCl}_{2}$. Filter-sterilized $0.2 \%(\mathrm{w} / \mathrm{v})$ arabinose (or glucose) was added when needed. For physiological studies related to sulfur lithotrophic functions, the cells were grown in MS medium $\left(\mathrm{NH}_{4} \mathrm{Cl}, 1 \mathrm{~g} ; \mathrm{Na}_{2} \mathrm{HPO}_{4}, 7.9 \mathrm{~g}\right.$; $\mathrm{KH}_{2} \mathrm{PO}_{4}, 1.5 \mathrm{~g} ; \mathrm{MgSO}_{4}, 0.5 \mathrm{~g}$ and $5 \mathrm{ml}$ trace metal solution per litre water; Vishniac \& Santer, 1957) supplemented with filter-sterilized $40 \mathrm{mM}$ thiosulfate (MST) or $18.5 \mathrm{mM}$ succinate (MSS).

Construction of the soxR:: $\Omega$-kanamycin insertion mutant strain. $\operatorname{sox} R$ was disrupted by inserting the kanamycin cassette derived from pUC4K (Amersham) through the recombinant suicide plasmid pKSRTKm by gene replacement. A $1.5 \mathrm{~kb}$ PCR amplicon consisting of the $V^{\prime} S R T^{\prime}$ genomic region was generated using the primer pair TR (5'-CGGAATTCGAAACACCCACCACGACAA-3') and VR (5'-GCTCTAGAGGCGAGACGAATGACAGAAG-3') with KCT001 genomic DNA by the aid of proofreading Taq polymerase. The purified amplicon was subjected to restriction digestion by EcoRI and XbaI, as the primer TR has an EcoRI and VR has a XbaI site in the $5^{\prime}$ region. The digested and subsequently purified fragment was ligated with the EcoRI- and XbaI-digested suicide vector pKAS32 (Skorupski \& Taylor, 1996). The ligated mixture was transformed into the $\lambda$-pir-containing competent E. coli SY327 strain (Miller \& Mekalanos, 1988). Recombinant colonies were selected and confirmed by both restriction digestion and PCR with insertspecific primer. The recombinant pKSRT suicide plasmid was digested with $X h o I$, for which there is one site within the inserted soxR gene of the $V^{\prime} S R T^{\prime}$ fragment. A SalI-digested kanamycin cartridge from pUC4K was introduced into the XhoI site of pKSRT. The resulting pKSRTKm plasmid was selected on kanamycin plates and confirmed by restriction digestion. The pKSRTKm-containing E. coli SY327 was conjugated with KCT001SR. The transconjugants with single crossovers were streptomycin sensitive because of the presence of $r p s L$ provided with pKAS32. The transconjugants with double crossovers were selected by their streptomycin-resistant phenotype. The recombinant strain was confirmed by PCR and Southern blotting.

Substrate-dependent oxygen consumption. KCT001 (wild-type) and KCT001SR:: $\Omega$ soxR (mutant) were grown in LB medium overnight at $30^{\circ} \mathrm{C}$. Experimental MST and MSS media were inoculated with equal amounts of overnight-grown LB culture. Growing cells were harvested at different time intervals by centrifugation, washed, and resuspended in sodium phosphate buffer (100 mM, pH 8.0). The sulfur-oxidizing activity of whole cells was determined polarographically with a biological oxygen monitor having a Clark-type oxygen

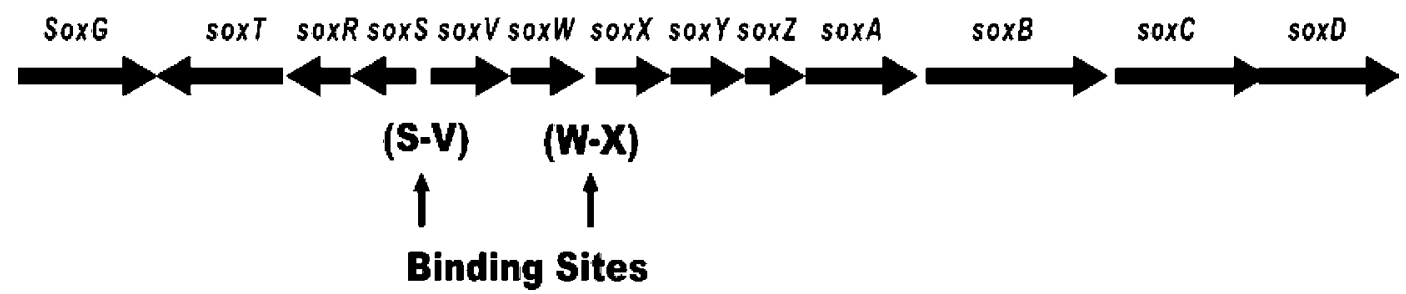

Fig. 1. Physical map of the sox gene cluster of $P$. salicylatoxidans KCT001. Horizontal arrows indicate the ORFs and their direction of transcription. ORFs are not in exact scale. Upward vertical arrows demarcate the two binding sites ( $s v$ and $w x$ ) of SoxR. 
Table 1. Bacterial strains and plasmids

\begin{tabular}{|c|c|c|}
\hline Strain or plasmid & Relevant characteristics & Reference/source \\
\hline \multicolumn{3}{|l|}{ Escherichia coli } \\
\hline XL-1 Blue & $\begin{array}{l}\text { recA1 lac endA1 gyrA46 thi hsdR17 supE44 relA1 }\left[\mathrm{F}^{\prime} \text { proAB }\right. \\
\left.\text { lacl }{ }^{\mathrm{q}} \mathrm{Z} \Delta \mathrm{M} 15 \operatorname{Tn} 10\left(\mathrm{Tet}^{\mathrm{r}}\right)\right]\end{array}$ & Bullock et al. (1987); Stratagene \\
\hline TOP10 & $\begin{array}{l}\mathrm{F}^{-} \text {mcrA } \Delta(m r r-h s d R M S-m c r B C) \text { p80lacZ } \Delta \mathrm{M} 15 \Delta \text { lacX74 deoR } \\
\text { recA1 araD139 } \Delta(\text { araA-leu }) 7697 \text { galU galK rpsL endA1 nupG }\end{array}$ & Invitrogen \\
\hline SY327 $\lambda$ pir & $\Delta($ lac pro $) \operatorname{argE}(\mathrm{Am})$ recA (Rif) nalA $\lambda$ pir & Miller \& Mekalanos (1988) \\
\hline M15 & K12 derivative & Qiagen \\
\hline \multicolumn{3}{|l|}{ Sulfur chemolithotrophs } \\
\hline $\begin{array}{l}\text { Pseudaminobacter } \\
\text { salicylatoxidans } \text { KCT001 }\end{array}$ & Wild-type, Sox ${ }^{+*}$ & $\begin{array}{l}\text { Deb et al. (2004); Mukhopadhyaya } \\
\text { et al. (2000); DSM } 13826\end{array}$ \\
\hline KCT001SR & $\operatorname{Sox}^{+} \operatorname{Sm}^{r} \operatorname{Rif}^{\mathrm{r}}($ spontaneous mutant of KCT001) & Mukhopadhyaya et al. (2000) \\
\hline KCT001SR $\Omega R$ & $\operatorname{soxR}:: \Omega \mathrm{Km}($ soxR-inactivated KCT001SR) & This study \\
\hline \multicolumn{3}{|l|}{ Plasmids } \\
\hline pUC4K & pUC vector carrying the kanamycin cassette from $\operatorname{Tn} 903$; $\operatorname{Kan}^{\mathrm{r}} \mathrm{Ap}^{\mathrm{r}}$ & Amersham \\
\hline pKAS32 & Cloning vector with dominant $r p s L$ gene & Skorupsky \& Taylor (1996) \\
\hline pKSRT & pKAS containing part of $\operatorname{sox} V$, soxS, soxR and part of soxT & This study \\
\hline pKSRTKm & pKSRT with soxR inactivated by kanamycin cassette & This study \\
\hline PQE30 & $\mathrm{Ap}^{\mathrm{r}} \mathrm{Cm}^{\mathrm{r}} \mathrm{T} 5$ promoter $[\mathrm{His}]_{6}$ & Qiagen \\
\hline pQER & soxR ORF cloned in BamHI-HindIII site of pQE30 & This study \\
\hline pBAD & $\mathrm{Ap}^{\mathrm{r}}$ ara promoter & Invitrogen \\
\hline pBADR & soxR ORF cloned in BamHI-HindIII site of pBAD & This study \\
\hline pSD5B & Promoter-probe vector; $\mathrm{Km}^{\mathrm{r}}$ & Jain et al. (1997) \\
\hline pSDSV & $\mathrm{S}-\mathrm{V}$ intergenic region cloned in $\mathrm{XbaI}$ site of pSD5B & This study \\
\hline pSDVS & $\begin{array}{l}\mathrm{S}-\mathrm{V} \text { intergenic region cloned in reverset orientation in } \mathrm{XbaI} \text { site } \\
\text { of } \mathrm{pSD} 5 \mathrm{~B}\end{array}$ & This study \\
\hline pSDWX & $\mathrm{W}-\mathrm{X}$ intergenic region cloned in $\mathrm{XbaI}$ site of $\mathrm{pSD} 5-\beta-\mathrm{Gal}$ & This study \\
\hline
\end{tabular}

${ }^{\star}$ Ability to oxidize reduced sulfur compounds and chemolithotrophic growth is denoted by Sox ${ }^{+}$.

electrode (Yellow Springs Instrument Co.) at $30^{\circ} \mathrm{C}$. The final assay volume was $3 \mathrm{ml}$ and the cells were suspended in $100 \mathrm{mM}$ phosphate buffer at $\mathrm{pH}$ 8.0. Calculations were made on the basis of an oxygen concentration of $236 \mu \mathrm{M}$ in air-saturated buffer at $30^{\circ} \mathrm{C}$ (Meulenberg et al., 1992). Oxygen consumption rates were corrected for chemical or auto-oxidation of substrates and endogenous respiration rates.

Construction of recombinant expression plasmids. The $\operatorname{sox} R$ gene was PCR amplified for in-frame insertion into the N-terminal His-tag expression vector pQE30 (Qiagen). The forward primer (SoxRN) (5'-GTCATAGGATCCATGCATGGGAACCCGCAA-3') that was used in the above amplification carried a unique $B a m \mathrm{HI}$ site at the $5^{\prime}$ end of the gene, while the reverse primer (SoxRC) (5'-GCCAGCAAGCTTCCTTGGCGGATTGTTATT-3') carried a HindIII site located 13 nucleotides downstream from the TAA translation stop codon. The amplified DNA fragment was digested with BamHI and HindIII and ligated into the same sites of pQE30 to generate the recombinant plasmid construct pQER, which was subsequently transformed into competent E. coli XL-1 Blue (Bullock et al., 1987). SoxR was also expressed from the tightly regulated arabinose-inducible promoter using the vector pBAD (Invitrogen). The BamHI- and HindIII-digested soxR-containing fragment of pQER was ligated with BglII- and HindIII-digested pBAD to generate recombinant construct pBADR. The inserted DNA fragments were sequenced from the expression vectors to check the coding frame and for any misincorporation of nucleotide(s) in the course of polymerization during PCR.
Expression and purification of recombinant SoxR. Recombinant SoxR was overproduced in E. coli M15 cells. The cells were grown at $37^{\circ} \mathrm{C}$ in $500 \mathrm{ml} \mathrm{LB}$ containing appropriate antibiotic selection up to an $\mathrm{OD}_{600}$ of 0.7. Expression of SoxR was induced by adding $1 \mathrm{mM}$ IPTG. In the case of expression from pBADR, induction was done by adding $0.2 \%(\mathrm{w} / \mathrm{v})$ arabinose. Whenever tight repression of expression from pBADR was necessary, $0.2 \%(\mathrm{w} / \mathrm{v})$ glucose was added in place of arabinose. For purification of recombinant SoxR, the pQE-based IPTG-inducible system (pQER) was preferred, as in this case the protein was tagged with six histidine residues. IPTG-induced E. coli cells harbouring pQER were grown for $4 \mathrm{~h}$, after which the cells were harvested, washed with $0.9 \%(\mathrm{w} / \mathrm{v}) \mathrm{NaCl}$, resuspended in lysis buffer $\left(50 \mathrm{mM} \mathrm{NaH}_{2} \mathrm{PO}_{4}\right.$, $300 \mathrm{mM} \mathrm{NaCl}$ and $10 \mathrm{mM}$ imidazole) and lysed by sonication. The insoluble materials were separated by centrifugation $(10000 \mathrm{~g})$. The soluble fraction was applied to a $\mathrm{Ni}^{2+}$-NTA agarose column (Qiagen) equilibrated with lysis buffer. The column was washed with 10 volumes of lysis buffer and the protein was eluted with a $20 \mathrm{ml}$ linear gradient of imidazole $(20-500 \mathrm{mM})$ in the same buffer. The fraction was assessed for its purity by $12.5 \%$ SDS-PAGE. Fractions containing SoxR protein were pooled and dialysed against storage buffer $\left(50 \mathrm{mM} \mathrm{NaH} \mathrm{PO}_{4}, 250 \mathrm{mM} \mathrm{NaCl}, 0.1 \mathrm{mM}\right.$ EDTA and $10 \%, \mathrm{v} / \mathrm{v}$, glycerol) for $10 \mathrm{~h}$ at $4{ }^{\circ} \mathrm{C}$.

Gel retardation assay. For the electrophoretic mobility shift assay (EMSA), promoter fragments derived from the intergenic region between $\operatorname{soxS}-\operatorname{soxV}(s v)$ and $\operatorname{sox} W-\operatorname{soxX}(w x)$ (Fig. 1) were amplified using $\gamma-{ }^{32} \mathrm{P}$-labelled primers SR (5'-GTCGCCACCATTACCAGTG- ${ }^{\prime}$ ) 
and VR ( $5^{\prime}$-GGCGAGACGAATGACAGAAG-3') for $s v$, and WF ( $5^{\prime}$ GCTCTAGAAGGAGTAGTTCACAGGGTTT- $\left.3^{\prime}\right)$ and XR (5'-GCTCTAGATCATATCTCTGCCCCTCCA-3') for $w x$, in PCR using the KCT001 genomic DNA as template. Primer labelling was done by kinasing $10 \mathrm{pmol}$ of the desired primer with $\left[\gamma^{32} \mathrm{P}\right] \mathrm{ATP}$ (BRIT, Bombay, India) and T4 polynucleotide kinase (New England Biolabs), the product being used directly in PCR after heat inactivation. The PCR product was purified using a PCR purification kit (Qiagen). The binding reaction mixture (30 $\mu$ final volume), unless mentioned otherwise, contained the desired amount of purified protein, $3 \mu \mathrm{l} 10 \times$ binding buffer $(100 \mathrm{mM}$ Tris/ $\mathrm{HCl} \mathrm{pH} 8,300 \mathrm{mM}$ $\mathrm{NaCl}, 30 \mathrm{mM} \mathrm{MgCl}, 1 \mathrm{mM}$ EDTA, $20 \%$, v/v, glycerol) and $1 \mu \mathrm{g}$ salmon sperm DNA. Reaction mixtures were preincubated for $10 \mathrm{~min}$ followed by a further $10 \mathrm{~min}$ incubation on ice after adding 10000 c.p.m. of labelled DNA amplicon. The reaction mixtures were separated on a $5 \%$ native polyacrylamide gel (following pre-run at $100 \mathrm{~V}$ for $1 \mathrm{~h})$ by electrophoresis in $0.5 \times$ Tris/borate buffer $(50 \mathrm{mM}$ Tris/borate, $1 \mathrm{mM}$ EDTA) at $200 \mathrm{~V}$ for $3-4 \mathrm{~h}$ at $4{ }^{\circ} \mathrm{C}$. Following electrophoresis, gels were vacuum dried and the bands were visualized by autoradiography. For quantification, intensities of bands corresponding to SoxR-bound and free DNAs were densitometrically estimated using an imaging densitometer (Bio-Rad GS-700).

DNase I footprint assay. DNase I footprint analysis was performed with the above-mentioned probe. Approximately 0.31 pmol labelled DNA was incubated with SoxR protein for $20 \mathrm{~min}$ at room temperature. Then $50 \mathrm{ng}$ DNase I (Sigma) was added and incubated for $3 \mathrm{~min}$ at room temperature. Digests were stopped with DNase I stop solution (50 mM Tris/ $\mathrm{HCl} \mathrm{pH} 8,50 \mathrm{mM}$ EDTA, $2 \%$, w/v, SDS and $0.4 \mathrm{mg}$ proteinase $\mathrm{K} \mathrm{ml}^{-1}$ ). Digested DNA fragments were resuspended in loading buffer [ $98 \%(\mathrm{v} / \mathrm{v})$ deionized formamide, $10 \mathrm{mM}$ EDTA, $0.025 \%(\mathrm{w} / \mathrm{v})$ xylene cyanol and $0.025 \%(\mathrm{w} / \mathrm{v})$ bromophenol blue], boiled for $5 \mathrm{~min}$ followed by rapid chilling and separated by gel electrophoresis on an $8 \%(\mathrm{w} / \mathrm{v})$ urea/Tris/borate/EDTA sequencing gel at $1200 \mathrm{~V}$ for 3.5-4 h. The gel was dried on Whatman paper and exposed to Kodak BioMax film. An A+G ladder was prepared with 0.31 pmol labelled DNA according to standard protocol (Sambrook \& Russell, 2001) and analysed along with the digested DNA.

Promoter construct and co-transformation. The $s v$ and $w x$ intergenic regions were amplified from KCT001SR genomic DNA with primer pairs SR1 (5'-GCTCTAGAGTCGCCACCATTACCAGTG- $3^{\prime}$ ) and VR1 (5'-GCTCTAGAGGCGAGACGAATGACAGAAG- $\left.3^{\prime}\right)$ for the $s v$ operator/promoter region, and WF1 $\left(5^{\prime}\right.$-GCTCTAGAAGGAGTAGTTCACAGGGTTT- $\left.3^{\prime}\right)$ and XR1 (5'GCTCTAGATCATATCTCTGCCCCTCCA-3') for the $w x$ operator/ promoter region. All the primers have $X b a \mathrm{I}$ sites in their $5^{\prime}$ ends. The $X b a I$-digested amplicons were cloned upstream of the lac $Z$ cartridge in the promoter-probe vector pSD5B, resulting in the recombinant plasmid pSDSV ( $s v$ promoter which expresses soxVW), pSDVS (containing the $s v$ region in the opposite orientation, soxSRT direction) and pSDWX ( $w x$ promoter which expresses soxX-D). To set up complementation experiments, promoter constructs (see Fig. 6) based on pSD5B (Jain et al., 1997) were cotransformed into E. coli along with either an IPTG- (pQER) or arabinose (pBADR)inducible SoxR construct. The cotransformed vector systems are compatible, as pSD5B replicates using a p15A origin and has kanamycin as a selectable marker, whereas pQER or pBADR uses a ColE1 origin and has ampicillin as marker. Cotransformed cells were thus selected on LB agar plates containing kanamycin and ampicillin $\left(50 \mu \mathrm{g} \mathrm{ml}^{-1}\right.$ each). Transformed colonies were grown in LB with kanamycin and ampicillin for promoter assays.

$\boldsymbol{\beta}$-Galactosidase assay. Overnight cultures of E. coli XL-1 Blue harbouring promoter constructs with or without soxR coexpression were grown under specified conditions and subjected to promoter assays as described by Sambrook \& Russell (2001). One millilitre of the culture was pelleted by centrifugation and suspended in $0.5 \mathrm{ml} \mathrm{Z}$ buffer $\left(\mathrm{Na}_{2} \mathrm{HPO}_{4}, 16.1 \mathrm{~g} ; \mathrm{NaH}_{2} \mathrm{PO}_{4}, 5.5 \mathrm{~g} ; \mathrm{KCl}, 0.75 \mathrm{~g} ; \mathrm{MgSO}_{4}\right.$, $0.24 \mathrm{~g}$ and $50 \mathrm{mM}$ mercaptoethanol per litre water). The cells were permeabilized by adding one drop of $0.1 \%(\mathrm{w} / \mathrm{v})$ SDS and two drops of chloroform with mixing. The reaction mixture contained $0.2 \mathrm{ml}$ of cells, $0.1 \mathrm{ml}$ of $8 \mathrm{mg} \mathrm{ml}^{-1}$ ONPG and $0.7 \mathrm{ml}$ of $\mathrm{Z}$ buffer. Enzyme activity was estimated from the release of nitrophenol, which was detected spectrometrically at $420 \mathrm{~nm}$ and was expressed in Miller units (Miller, 1972)

Immunological analysis. To monitor the induced synthesis of SoxR in E. coli Western blot analysis using anti-His antibody (Qiagen) was performed. Equal amounts of cytosolic proteins extracted from E. coli cells expressing $\mathrm{His}_{6}$-tagged SoxR were resolved on $12.5 \%$ polyacrylamide gels and subsequently transferred electrophoretically to Nytran membrane at $80 \mathrm{~mA}$ constant current for $50 \mathrm{~min}$ according to standard protocol (Towbin et al., 1979). The membranes were probed with anti-His antibody as primary antibody and anti-rabbit IgG-alkaline phosphatase conjugate as the secondary antibody. A chromogenic (NBT-BCIP) method was used to detect the desired band, following the instruction manual (Roche Applied Science).

Protein cross-linking assays. Multimer formation was studied using glutaraldehyde cross-linking assays (Randell \& Coen, 2004). Purified SoxR protein was incubated for $10 \mathrm{~min}$ with $0.005 \%$ and $0.01 \%(\mathrm{v} / \mathrm{v})$ glutaraldehyde and analysed by SDS-PAGE. To investigate the effect of SoxR binding to DNA sequences on the multimerization of the protein, PCR-amplified DNA fragments representing SoxR-binding sites were incorporated in increasing concentrations in the cross-linking assay. The protein profile was analysed by SDSPAGE and visualized by staining with Coomassie blue.

Dynamic light scattering on SoxR. The dynamic light scattering experiment was performed in a Zetasizer Nano ZS instrument (Malvern Instruments). The measurements were carried out in $50 \mathrm{mM}$ phosphate buffer ( $\mathrm{pH} 8.0$ ) containing $100 \mathrm{mM} \mathrm{NaCl}$ and $10 \%(\mathrm{v} / \mathrm{v})$ glycerol. The purified protein sample was passed twice through a filter membrane of $0.22 \mu \mathrm{m}$ pore size. The protein concentration of the sample was then measured by the Lowry method and the sample diluted accordingly during the light-scattering measurements. All the light-scattering measurements were performed at $25^{\circ} \mathrm{C}$. A single run represents an average of 20 independent 10 s runs.

\section{RESULTS}

\section{Effect of soxR inactivation on expression of the sox locus}

soxR of $P$. salicylatoxidans KCT001 was insertionally inactivated, and the sulfur utilization capability and growth of the resulting mutant were compared with those of the wildtype. The cells were grown in either heterotrophic medium (MSS) or autotrophic medium (MST). At defined intervals, cells were harvested and the level of Sox activity monitored by incubating the cells transiently in the presence of thiosulfate. The $\mu \mathrm{mol}$ oxygen consumed per minute per mg total protein in the process of oxidizing thiosulfate was used as the parameter for Sox activity. The wild-type showed no activity in heterotrophic medium, indicating tight repression of the operon in the absence of thiosulfate (Fig. 2a). In contrast, the mutant showed high level of activity in heterotrophic medium, comparable to the activity observed when the wild-type was grown under autotrophy (Fig. 2a). These results indicate clearly that SoxR acts as the repressor. 

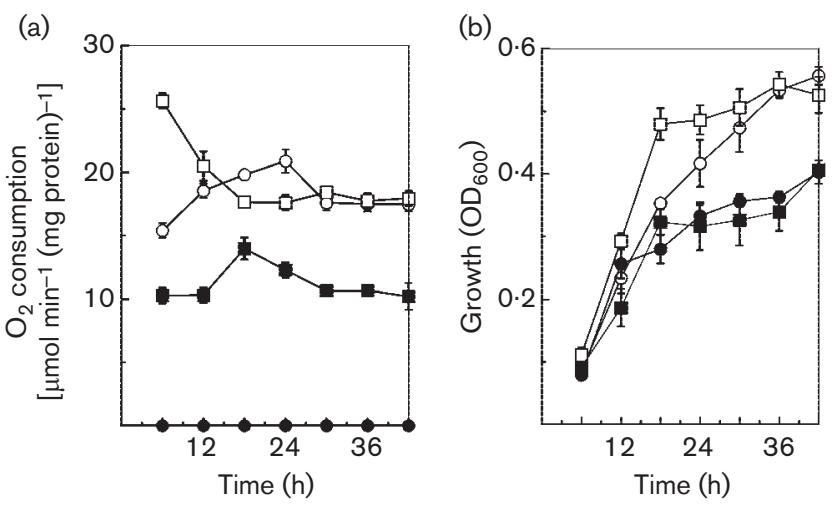

Fig. 2. Sox activity (a) and cellular yield (b) of $P$. salicylatoxidans KCT001 and the soxR-inactivated mutant grown in heterotrophic and autotrophic media. Overnight-grown KCT001 and its mutant were inoculated into the desired media and samples were removed at defined time intervals. The Sox activity, expressed as oxygen consumption, was measured by incubating the harvested cells in an assay buffer containing thiosulfate for $5 \mathrm{~min} . \mathrm{O}_{2}$ consumption (a) and growth (b) of heterotrophically grown ( $)$ and autotrophically grown $(\bigcirc)$ wild-type and heterotrophically grown (ם) and autotrophically grown ( $\square$ ) mutant.

\section{DNA-binding activity of SoxR}

The recombinant SoxR was overexpressed and subsequently purified for investigating its DNA-binding properties. Two SoxR-binding regions were chosen based on the DNAbinding studies performed with Paracoccus pantotrophus. The binding regions were designated either $s v$ or $w x$, representing the intergenic regions between soxS-soxV and so $x W-$ sox $X$, respectively. Concentration-dependent increase in SoxR binding to $s v$ and $w x$ regions was observed (Fig. 3). In the case of $w x$ and $s v, 50 \%$ of the probe was bound at SoxR concentrations of $150 \mathrm{nM}$ and $70 \mathrm{nM}$, respectively. These values therefore represent approximate dissociation constants for SoxR binding to the respective sites. The binding was analysed by fitting the data into a two-site binding model represented by the following equations:

$$
\begin{aligned}
& F_{0}=1 /\left(1+A_{1} \cdot X+A_{2} \cdot X^{2}\right) \\
& F_{1}=A_{1} \cdot X /\left(1+A_{1} \cdot X+A_{2} \cdot X^{2}\right) \\
& F_{2}=A_{2} \cdot X^{2} /\left(1+A_{1} \cdot X+A_{2} \cdot X^{2}\right)
\end{aligned}
$$

(a)

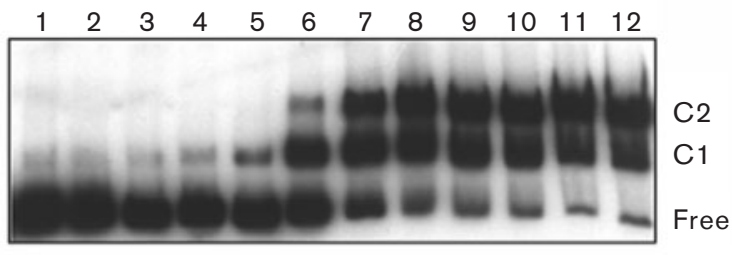

(b)

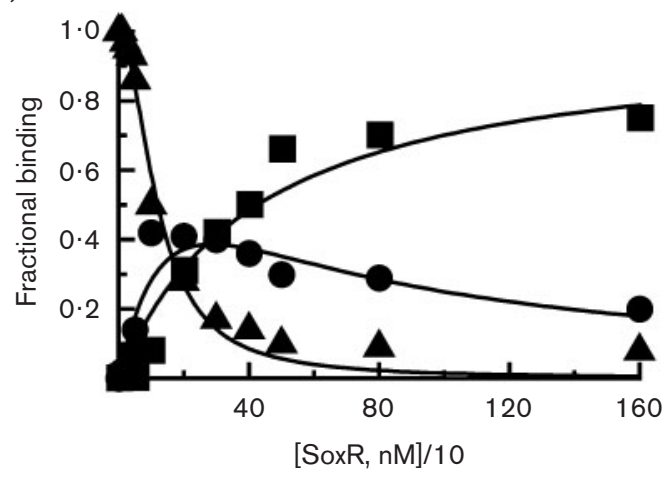

(c)

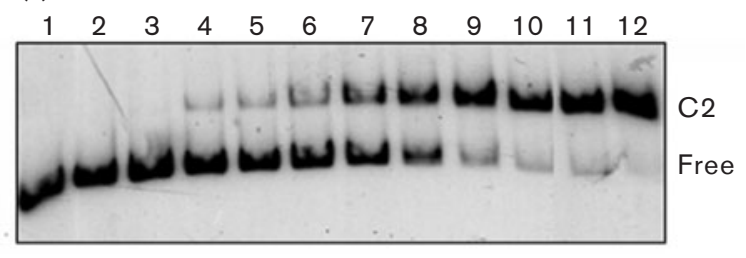

(d)

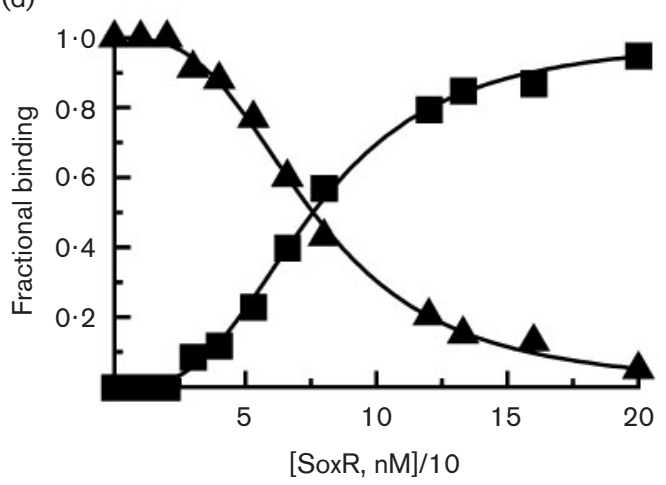

Fig. 3. Interaction of SoxR with its binding sites in the sox operon. (a) EMSAs with $w x$ site: lanes 1-12 were supplied with increasing amounts $(0,10,20,30,40,50,100,300,400,500,800,1600 \mathrm{nM}$, respectively) of SoxR. (b) Binding data were fitted to a two-site model as described in Results. $\boldsymbol{\Lambda}$. Free probe; $\mathbf{\square}, \mathrm{C} 1$ complex; $\boldsymbol{\bullet}, \mathrm{C} 2$ complex. (c) Interaction of SoxR with $s v$ binding sites. EMSAs with sv intergenic region. Binding was carried out with increasing concentrations of SoxR (lanes 1 to $12: 0,8,16,25,33,44,55,66,100,111,132$ and $166 \mathrm{nM}$ SoxR, respectively) (d) Binding data were fitted to a two-site model as described in Results. $\boldsymbol{\Delta}$, Free probe; $\mathbf{\square}, \mathrm{C} 2$ complex. 
$F_{0}, F_{1}$ and $F_{2}$ represent the fraction unbound and fraction in the liganded states ( 1 or 2$), A_{1}, A_{2}$ are the macroscopic association constants and $X$ is the concentration of free ligand. The values of $A_{1}$ and $A_{2}$ thus obtained in the case of $w x$ were approximately $4 \times 10^{7} \mathrm{M}^{-1}$ and $10^{16} \mathrm{M}^{-2}$, respectively. When a binding phenomenon involving two sites is non-cooperative it is expected that $A_{2}=\left(A_{1}^{2}\right) / 4$. However, it is apparent that $A_{2}>\left(A_{1}^{2}\right) / 4$; hence the phenomenon is cooperative. In the case of $s v$, which gives a single complex, curve fitting was attempted using two- as well as single-site binding models. The data could be fitted to the two-site model, described above (Fig. 3b, d), but not adequately to the single-site model (analysis not shown). This suggests that binding to $s v$, like that to $w x$, also involves two sites. In the case of $s v A_{2}$ was $10^{16} \mathrm{M}^{-2}$ but $A_{1}$ became vanishingly small and could not be accurately determined. The cooperativity of binding in the case of the $s v$ region is thus even higher than for $w x$. The complex that is visible in the case of $s v$ is possibly $\mathrm{C} 2$. The $\mathrm{C} 1$ complex is not detectable in the case of $s v$, apparently due to the phenomenon being strongly cooperative, resulting in suppression of the $\mathrm{C} 1$ complex.

\section{Defining the core binding sequences}

To identify the exact binding sites of the transcription regulator SoxR within the $s v$ and $w x$ promoter regions, DNase I footprinting experiments were performed using the PCR amplicons used in the EMSA. Addition of SoxR to the sample resulted in distinct DNase I footprints. In the case of $w x$ two distinct but closely juxtaposed regions could be identified (Fig. 4a). However, the two sites seem to have different affinities (Fig. $4 \mathrm{~b}$ ). The high-affinity site gave footprints at relatively low concentrations. In contrast to $w x$ the $s v$ region gave a single footprint (Fig. 4c). This is consistent with the single complex demonstrated in the EMSA. The core elements (Fig. 4d) thus identified were then synthesized and SoxR binding with these segments was tested. Both the core elements were bound to SoxR (Fig. 5a, b). The binding patterns were similar to those of the larger probes used in the initial EMSA experiments. However, it may be noted that in the case of $w x$ core the binding became even more cooperative, as indicated by the strong suppression of the intermediate complex C1 (Fig. 5b).

\section{Reporter assays for Sox promoter activity in the presence of SoxR}

Reporter constructs were made in which the promoter regions of $w x$ and $s v$ were fused in-frame to $l a c Z$ in a vector which replicates utilizing the p15A origin of replication, giving rise to $\mathrm{pSDWX}$ and $\mathrm{pSDSV}$ or pSDVS respectively (Table 1, Fig. 6). To supply SoxR in trans the IPTGinducible SoxR expression plasmid pQER was cotransformed along with the promoter constructs. Reporter gene expressions were then assayed in the absence and the presence of pQER. In the absence of SoxR a high level of activity was observed in the case of $s v$ and $w x$ and a moderate level in the case of $v s$. When reporter gene expression was monitored after cotransformation of $\mathrm{pQER}$, it was observed that without addition of IPTG, where expression is expected at the basal level, efficient repression (10-20-fold) occurred. Introduction of IPTG should have given further repression but in fact the opposite happened. Repression seemed to be relieved as increasing SoxR accumulated in the system (Fig. 7a). The phenomenon was also observed in the case of a time-course experiment (Fig. 7b), where it can be seen that following addition of IPTG, a time-dependent derepression was observed with increasing amount of SoxR (Fig. 7c). The results show that a basal level of expression apparently due to leaky protein expression was sufficient to repress promoter activity. To further verify that the efficient repression observed above was indeed due to leaky expression, a parallel experiment was performed using the tightly regulated promoter provided in the PBAD series of vectors. In this case leaky expression can be completely eliminated by the use of glucose in the absence of arabinose. The results show that under such tightly regulated conditions there is no repression (Fig. 7d), which confirms that the repression observed in the case of PQER was indeed due to basal expression of SoxR. However, addition of arabinose did show strong repression. The SoxR protein therefore is most active at low concentrations and seems to lose repressor activity at higher concentrations.

\section{Dimerization of SoxR}

Initial investigations using SDS-PAGE analyses and subsequent immunoblotting indicated the existence of a band corresponding to the dimer (Fig. 8a). To investigate the ability of SoxR to form dimers and multimers a glutaraldehyde cross-linking experiment was performed. The results showed efficient cross-linking and the formation of multimers, of which the dimeric form was predominant (Fig. 8b). Considering that SoxR interaction with $s v$ is highly cooperative, the possibility that $s v$ promotes dimerization was tested by incorporating increasing doses of $s v$ DNA in a cross-linking experiment. The results showed a dose-dependent increase in the intensity of cross-linked dimer (Fig. 8c). This gradual increase of SoxR dimer in the presence of the binding sequence demonstrated that repressor SoxR interacts with it as a dimer.

The process of multimerization was also examined using dynamic light-scattering experiments. Fig. 8(d) shows the distribution of species having a different hydrated diameter at two protein concentration: $37 \mu \mathrm{M}$ and $150 \mu \mathrm{M}$. Two peak hydrated diameter values were obtained, with values of approximately $8 \mathrm{~nm}$ and $32 \mathrm{~nm}$. The results indicate the presence of two populations with respect to multimerization.

\section{DISCUSSION}

Chemolithotrophic sulfur oxidation is induced by reduced sulfur compounds like thiosulfate, in the absence of which (heterotrophic growth) no sulfur-oxidizing activity is detectable. On the other hand, autotrophically grown cells show high levels of sulfur-utilizing activities. Thus any 


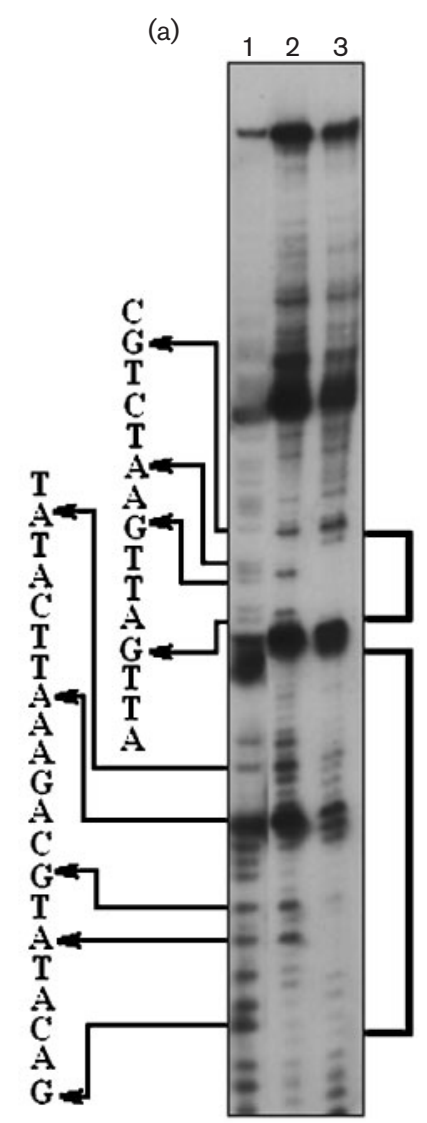

(b)

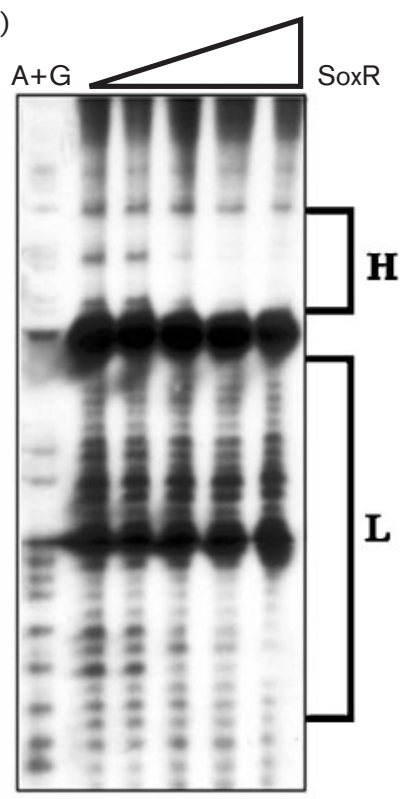

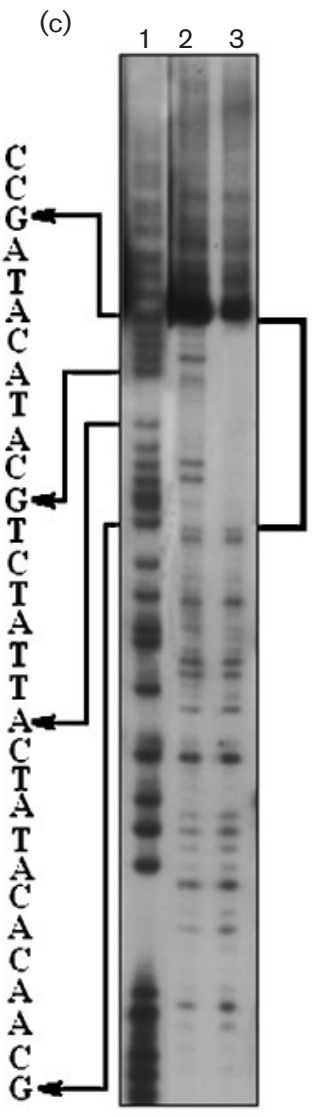

(d)

SV site:

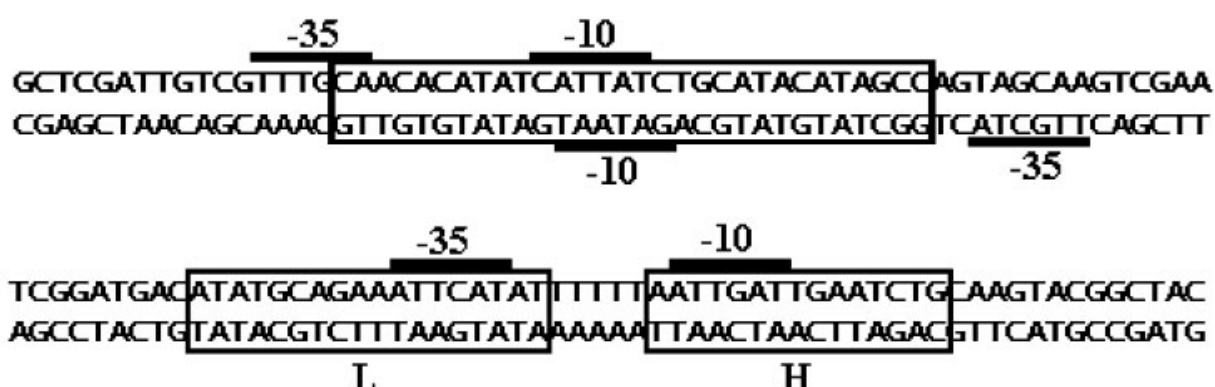

$\mathrm{L}$
$\mathrm{H}$

Fig. 4. DNase I protection assay to determine SoxR-binding sites in the $w x(\mathrm{a}, \mathrm{b})$ and $s v(\mathrm{c})$ regions. The binding-site sequences are indicated by brackets. Footprinting was performed using $5 \mu \mathrm{M}$ SoxR in $\mathrm{A}$ and $\mathrm{C}$. In the case of (b) the concentration of SoxR was increased progressively $(0,1,2,3$ and $5 \mu \mathrm{M})$. Lane 1 in each case represents $A+G$ ladder, 2 is DNase I ladder of free probe and 3 is DNase I ladder SoxR-bound probe. (d) Location of the binding sequences (boxes) in the $s v$ and $w x$ regions, $\mathrm{H}$ and $\mathrm{L}$ stand for high- and low-affinity site. The black bars represent the putative -35 and -10 sequences.

mutant that becomes constitutive must possess a level of activity under heterotrophic conditions that can match the level obtained by the wild-type under autotrophic conditions. In a previous study using Paracoccus pantotrophus, it was shown that an insertion within soxS, the gene immediately upstream of $\operatorname{soxR}$, resulted in a low level of constitutive expression (about $10 \%$ ) under heterotrophic conditions (Rother et al., 2005). Since this low level of constitutive expression could be repressed by complementation with $\operatorname{soxR}$, it was concluded that the phenotype was due to a polar effect of the soxS mutation on soxR. In this study, it has been demonstrated that direct inactivation of $\operatorname{sox} R$ resulted in a relatively higher (greater than $60 \%$ ) level of constitutive expression under heterotrophic conditions. The slight reduction in activity relative to the wild-type is possibly due to marginal retardation in growth rate 
(a)

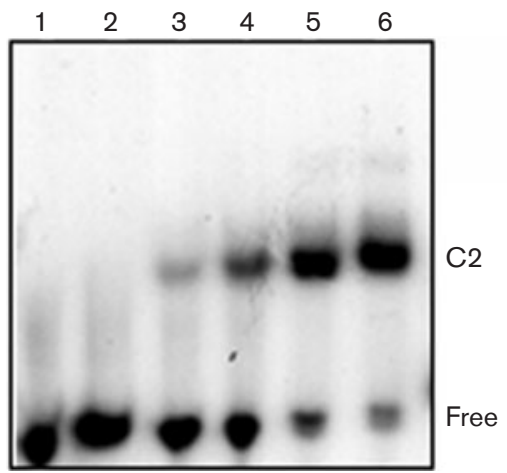

(b)

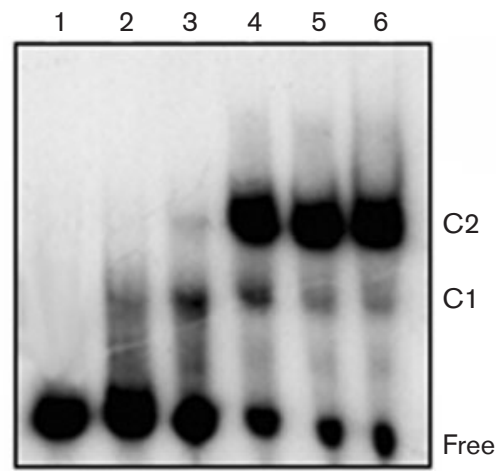

Fig. 5. EMSA of the core-binding region with SoxR. (a) Binding with the sv site. Binding was carried out with increasing concentrations of SoxR (lanes 1 to 6: 0, 6, 30, 45, 90 and $180 \mathrm{nM}$ SoxR, respectively). (b) Binding with the $w x$ site. Binding was carried out with increasing concentrations of SoxR (lanes 1 to 6: 0, 6, 30, 150, 300 and $600 \mathrm{nM}$ SoxR, respectively).
(Fig. 2b). Under autotrophic (and also mixotrophic, data not shown) conditions, nearly $100 \%$ wild-type level of activity was observed in the soxR mutant as compared to only $18 \%$ in the case of the soxS mutant. These observations suggest that the phenotype reported earlier probably arises from partial impairment of soxR function whereas in this study the inactivation appears to be complete. In the case of the mutant reported here, it is unlikely that insertion in soxR had any effect on soxS, since it is upstream of soxR. Hence the constitutive phenotype of the KCT001 soxR mutant appears, by and large, to be soxS independent. The same argument can not be applied to the downstream gene soxT, which could potentially be affected due to insertion in soxR. However, it may be noted that the mutant did not show the delayed Sox phenotype (Lahiri et al., 2006) and therefore apparently there is no polar effect on soxT.

SoxR was earlier demonstrated to bind to two intergenic regions within the sox locus of Paracoccus pantotrophus. In this study the binding of Pseudaminobacter salicylatoxidans KCT001 SoxR to the corresponding sites was examined. The binding isotherms presented in this study support a two-site model, as in both cases the data could be fitted to two-site binding equations. The binding was cooperative in both cases but in the case of $s v$ cooperativity was significantly greater than for $w x$, as is evident from the complete suppression of an intermediate complex in this case. The cooperativity may also be dictated by DNA conformation. It is interesting to note that when the minimal core sequence was used the cooperativity seemed to increase in the case of $w x$, as is indicated by the substantially diminished intensity of the intermediate band. The size of the core sequence (44 bp) is below the persistent length of DNA, which is considered to be about 100 bp (Shore et al., 1981), and hence the core sequence is likely to be more rigid than the longer sequence. The rigidity may result in facilitated interactions between bound monomer, causing increased cooperativity. These differences indicate that binding could be potentially regulated by the flexibility of the DNA.

The two-site model that has been proposed on the basis of mathematical derivations is supported strongly by footprinting data, particularly in the case of $w x$, where two distinct footprints were visible, one of which represented a high-affinity and the other a low-affinity interaction site. In the case of $s v$ only one footprint was obtained, which is

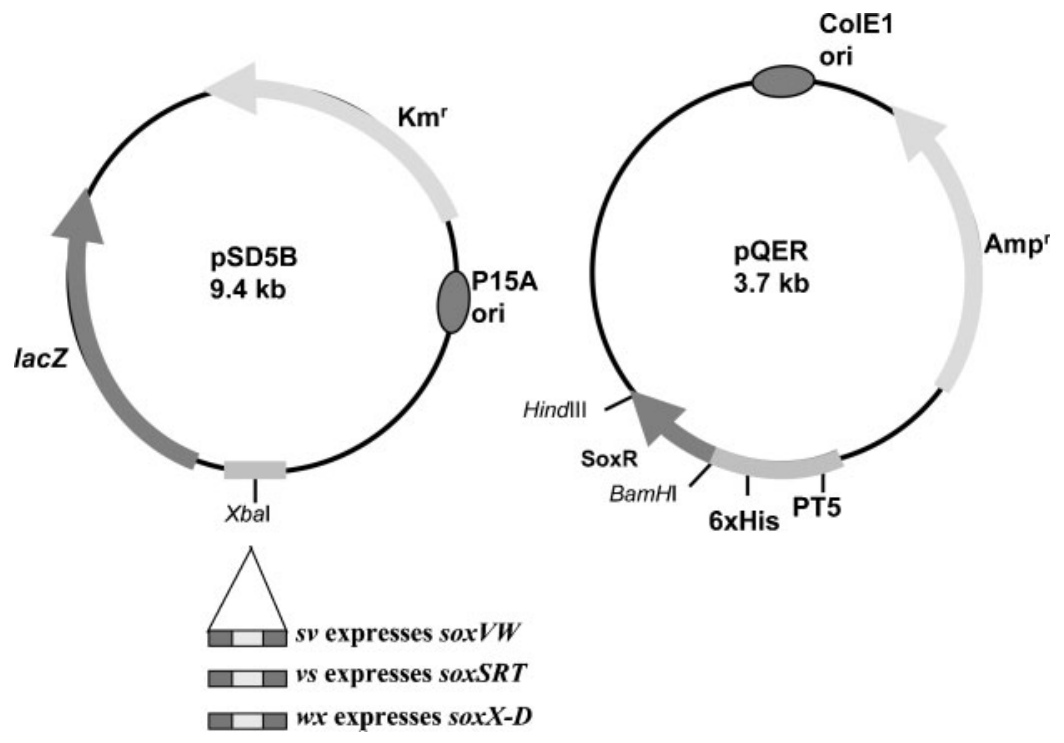

Fig. 6. Physical map of the reporter plasmid pSD5B and the recombinant SoxR expression vector $\mathrm{PQER}$. 
(a)

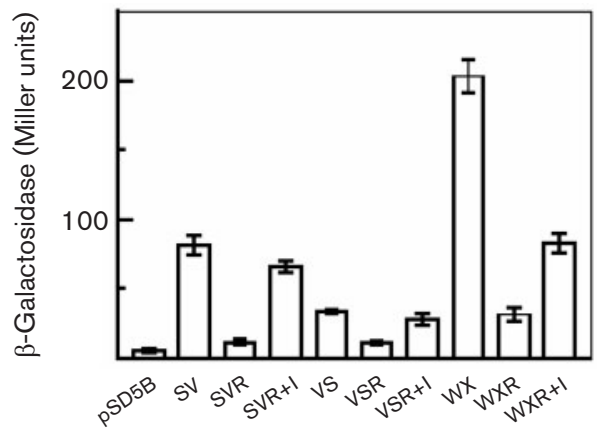

(b)

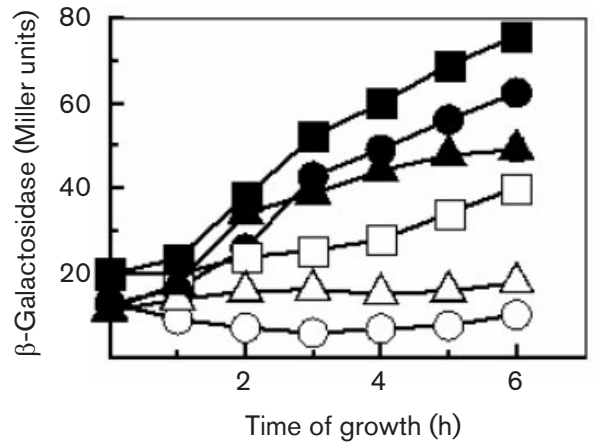

(d)
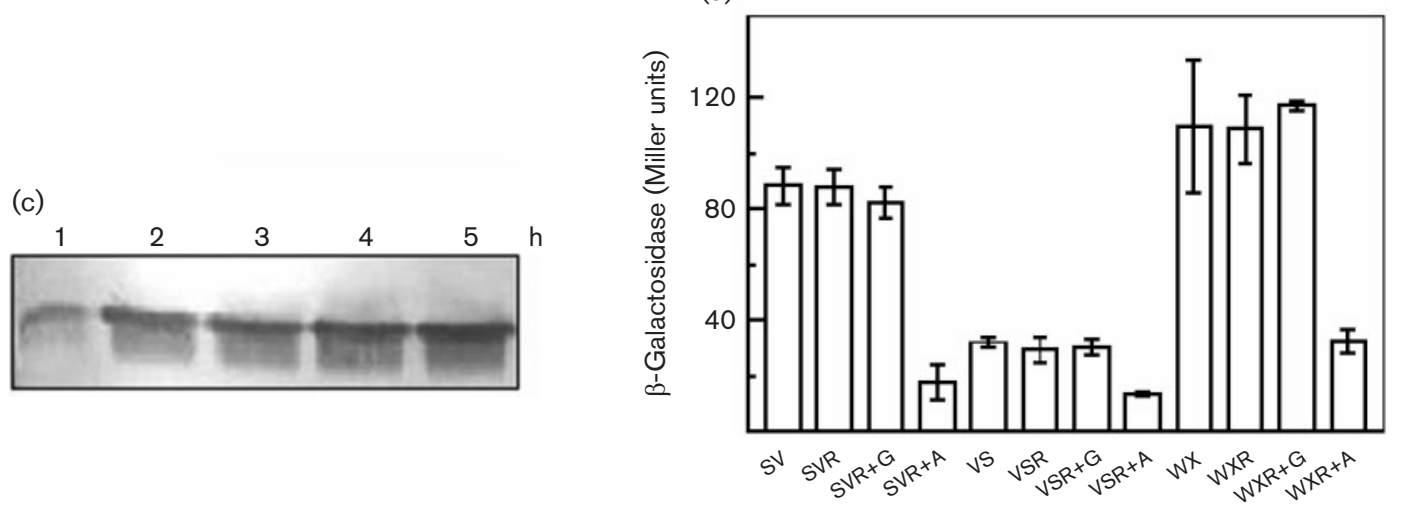

Fig. 7. Reporter assays for determining SoxR function. (a) E. coli XL-1 Blue transformed with promoter constructs pSDSV, pSDVS and pSDWX, either alone or in combination with SoxR expression vector pQER was assayed for the level of lac $Z$ under uninducing or inducing $(+\mathrm{l})$ conditions. The combinations tested were pSD5B, pSDSV (SV), pSDSV + pQER (SVR), pSDSV + pQER induced by IPTG (SVR + I), pSDVS (VS), pSDVS + pQER (VSR), pSDVS + pQER induced by IPTG (VSR + I), pSDWX (WX), pSDWX + pQER (WXR) and pSDWX+pQER induced by IPTG (WXR+l). (b) $\beta$-Galactosidase assay at different times of growth of $E$. coli cells harbouring either pSDWX (squares), pSDVS (triangles) or pSDSV (circles) in combination with pQER. Solid symbols are for IPTG-induced and open symbols are for non-induced cells. (c) Immunoblot analysis of SoxR present in equal amounts of cell-free extract of IPTG-induced E. coli cells harbouring both reporter and expression plasmids at different time points. (d) E. coli strain TOP10 transformed with promoter constructs pSDSV, pSDVS and pSDWX, either alone or in combination with SoxR expression vector pBADR was assayed for the level of lacZ under uninducing, repressing $(+G)$ or inducing $(+A)$ conditions. The combinations tested were pSDSV (SV), pSDSV + pBADR (SVR), pSDSV + pBADR repressed by glucose (SVR+G), pSDSV + pBADR induced by arabinose (SVR+A), pSDVS (VS), SDVS + pBADR (VSR), pSDVS + pBADR repressed by glucose (VSR+G), pSDVS + pBADR induced by arabinose $(V S R+A), \quad p S D W X \quad(W X), \quad p S D W X+p B A D R \quad(W X R), \quad p S D W X+p B A D R$ repressed by glucose $(W X R+G)$ and pSDSV + pBADR induced by arabinose $(W X R+A)$.

consistent with the single complex observed in the EMSA. It is however most likely that the binding at $s v$, like that at $w x$, represents a dimeric complex. This is evident not only from the binding curve but also from theoretical modelling studies (Bagchi et al., 2005), which show that this region can form a stable dimeric complex. In addition, the observation that $s v$ DNA promotes dimerization of SoxR, as evident from the cross-linking studies, gives further support to a dimeric site model. It is interesting to note that the $s v$ promoter-operator appears to have a degree of symmetry, with two CATA sequences being positioned at equivalent sites on either side of the centre of symmetry (Fig. 9). A similar organization was also shown in the case of Paracoccus pantotrophus. This symmetrical disposition is probably necessary as the promoter is a bi-directional one. Hence, although SoxR binds to both the loci $s v$ and $w x$, the binding patterns are dissimilar; this is probably a reflection of the fact that the two promoters $s v$ and $w x$ function in different contexts. The $w x$ promoter drives the expression of genes directly involved in sulfur oxidation. In this case a relatively more subtle regulation is perhaps required as the gene products perform an intricate metabolic function under conditions of autotrophy. In contrast, in the case of $s v$, which controls the expression of genes encoding auxiliary proteins required for Sox function, the regulation need not be 'rheostatic'; on the other hand an abrupt repression or derepression may be required. Cooperative mechanisms generally cater to such abrupt situations and therefore it 
(a)

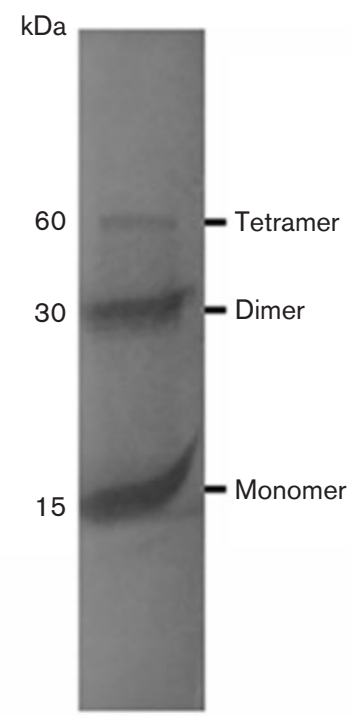

(c)

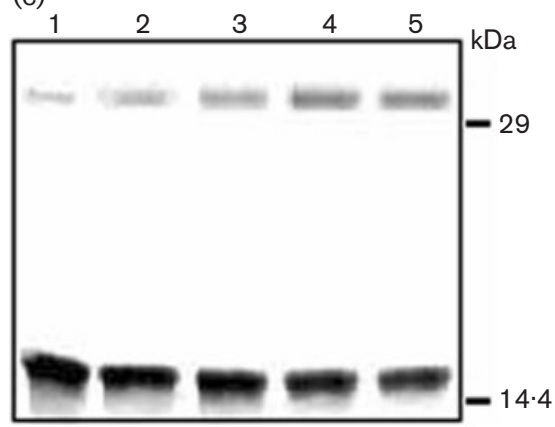

(b)

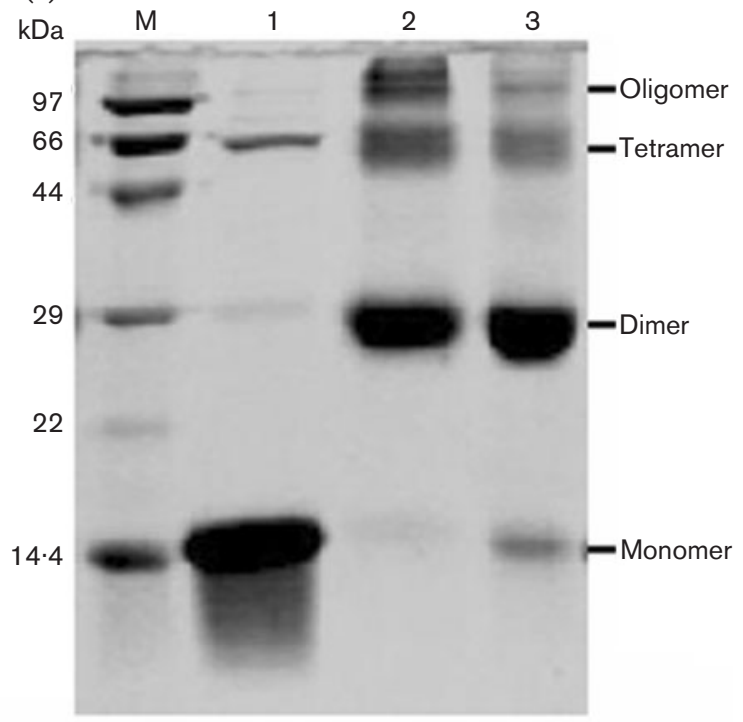

(d)

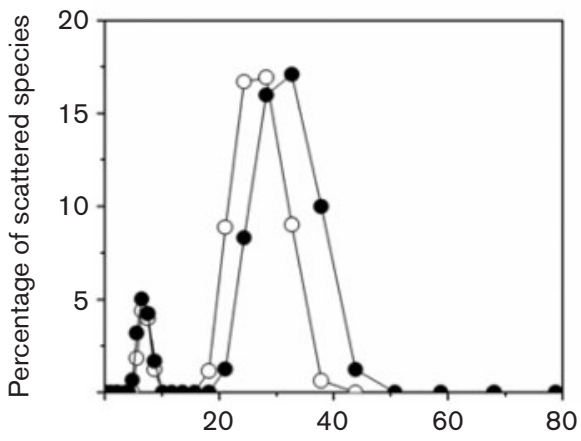

Hydrated diameter (nm)

Fig. 8. Multimeric nature of SoxR. (a) Immunoblotting of purified His-tagged SoxR with anti-His antibody. (b) SDS-PAGE profile of glutaraldehyde cross-linked SoxR. Lane M, molecular mass markers; lanes 1, 2 and 3, cross-linked SoxR with $0 \%$, $0.01 \%$ and $0.005 \%(\mathrm{v} / \mathrm{v})$ glutaraldehyde, respectively. (c) Glutaraldehyde cross-linking of SoxR in the presence of increasing amount of sv DNA. SoxR was incubated for $10 \mathrm{~min}$ with the DNA; $0.01 \%(\mathrm{v} / \mathrm{v})$ glutaraldehyde was added with the reaction mixture just before sample buffer was added. Samples were boiled for further SDS-PAGE analysis. Lanes 1-5 represent cross-linking in the presence of $0,0.5,1,1.5,2 \mu \mathrm{g} s v \mathrm{DNA}$, respectively. (d) Dynamic light-scattering experiments carried out at $37 \mu \mathrm{M}(\bigcirc)$ and $150 \mu \mathrm{M}(\bullet)$ of SoxR, respectively. The percentage of scattered species was plotted against the hydrated diameter of the protein. In each experiment, the output of a single run is an average of 20 independent scans of $10 \mathrm{~s}$ duration. The data presented are means of five independent measurements.

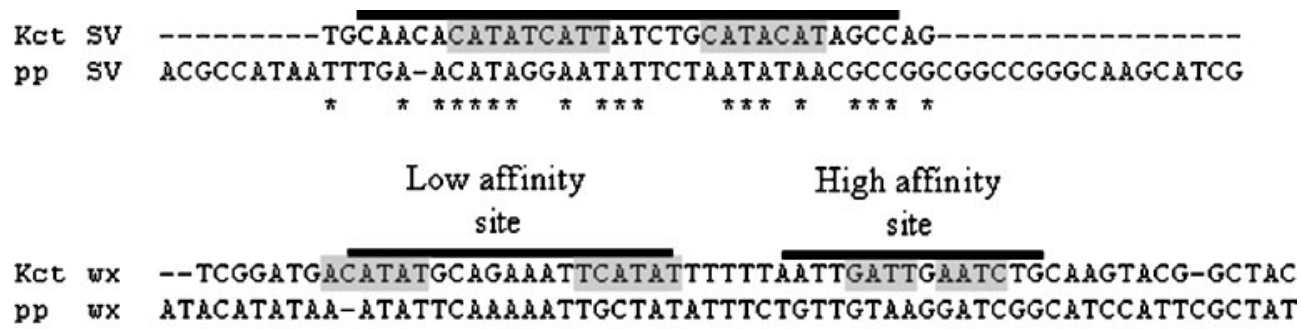

Low affinity

site

Ket wX --TCGGATGACATATGCAGAAATCATATTTTTAATTGATTGAMTTGCAAGTACG-GCTAC

pp wX ATACAT\&TAA-\&TATTCA\&AAATGCTATATTTCTGTTGTA\&GGATCGGCATCCATTCGCTAT

Fig. 9. Alignment of the core SoxR-binding regions of KCT001 (Kct) with those of Paracoccus pantotrophus (pp). The bar on the sequence represents the DNase I protected region by SoxR. The shaded sequences are near-exact repeats. 
probably makes sense that the binding to $s v$ is highly cooperative.

The various pieces of evidence reported in this study and the previous attempts to derive a model for SoxR binding suggest the importance of dimerization. Using several methods the efficient dimerization of SoxR has been demonstrated here for the first time. Cross-linking experiments clearly indicated the formation of dimer. Light-scattering experiments indicated the presence of two species, the larger one having a four times larger diameter. Considering that the volume should be proportional to the diameter cubed and that mass is proportional to volume, it appears, with some approximation, that a fourfold increase in diameter reflects a twofold increase in mass. The process of dimerization, although it takes place spontaneously, is further stimulated in the presence of binding sequences, $s v$ DNA in particular. The differences in the binding patterns to $s v$ and $w x$ can also be explained on the basis of dimerization. It may be noted that in the case of $w x$ two sites, a high-affinity and a lowaffinity one, can be clearly demarcated. The two sites, although located side by side, are separated by a couple of nucleotides. In such a situation it appears that the highaffinity site is engaged first followed by the low-affinity site. Once the two sites are occupied the monomers interact with each other, resulting in cooperativity. The $s v$ site on the other hand appears symmetrical, with two sites located side by side without any apparent gap. It is extremely difficult to understand the exact sequence of events in such cases of highly cooperative interaction, but the present account of the $s v$ site binding is consistent with earlier theoretical findings (Bagchi et al., 2005).

The dissociation constants appeared to be in the nanomolar order, which may be considered as sufficiently strong. Such strong interactions mean that the amount of SoxR required for saturation binding is extremely small. That SoxR is indeed an efficient repressor at low concentrations is evident from the reporter assays performed in E. coli. The basal level of expression produced due to leaky expression was enough to bring about substantial repression. Interestingly, repression was reversed as the level of SoxR was increased, thereby indicating that SoxR could become inactive at higher concentrations. This could either be due to the formation of inactive aggregates or have other causes not clear at present.

\section{ACKNOWLEDGEMENTS}

S. M., S. C. and B. D. are grateful to CSIR for their research fellowships. This paper is dedicated to the memory of P. Roy, who initiated this study before his untimely demise. We thank P. K. Chakrabartty and Wriddhiman Ghosh for going through the manuscript.

\section{REFERENCES}

Appia-Ayme, C. \& Berks, B. C. (2002). SoxV, an orthologue of the CcdA disulfide transporter, is involved in thiosulfate oxidation in
Rhodovulum sulfidophilum and reduces the periplasmic thioredoxin SoxW. Biochem Biophys Res Commun 296, 737-741.

Appia-Ayme, C., Little, P. J., Matsumoto, Y., Leech, A. P. \& Berks, B. C. (2001). Cytochrome complex essential for photosynthetic oxidation of both thiosulfate and sulfide in Rhodovulum sulfidophilum. J Bacteriol 183, 6107-6118.

Bagchi, A., Roy, D. \& Roy, P. (2005). Homology modeling of a transcriptional regulator SoxR of the lithotrophic sulfur oxidation (Sox) operon in $\alpha$-Proteobacteria. J Biomol Struct Dyn 22, 571-578.

Bardischewsky, F. \& Friedrich, C. G. (2001). The shxVW locus is essential for oxidation of inorganic sulfur and molecular hydrogen by Paracoccus pantotrophus GB17: a novel function for lithotrophy. FEMS Microbiol Lett 202, 215-220.

Bullock, W. O., Fernandez, J. M. \& Short, J. M. (1987). XL1-Blue: a high efficiency plasmid transforming recA Escherichia coli strains with beta-gatactosidase selection. BioTechniques 5, 376-378.

Deb, C., Stackebrandt, E., Padella, S., Saha, A. \& Roy, P. (2004). Phylogenetically diverse new sulfur chemolithotrophs of $\alpha$ Proteobacteria isolated from Indian soils. Curr Microbiol 48, 452-458.

Friedrich, C. G. (1998). Physiology and genetics of sulfur-oxidizing bacteria. Adv Microb Physiol 39, 235-289.

Friedrich, C. G., Quentmeier, A., Bardischewsky, F., Rother, D., Kraft, R., Kostka, S. \& Prinz, H. (2000). Novel genes coding for lithotrophic sulfur oxidation of Paracoccus pantotrophus GB17. J Bacteriol 182, 4677-4687.

Friedrich, C. G., Rother, D., Bardischewsky, F., Quentmeier, A. \& Fischer, J. (2001). Oxidation of reduced inorganic sulfur compounds by bacteria: emergence of a common mechanism? Appl Environ Microbiol 67, 2873-2882.

Jain, S., Kaushal, D., Dasgupta, S. K. \& Tyagi, A. K. (1997). Construction of shuttle vectors for genetic manipulation and molecular analysis of mycobacteria. Gene 190, 37-44.

Kelly, D. P. (1989). Physiology and biochemistry of unicellular sulfur bacteria. In Autotrophic Bacteria, pp. 193-217. Edited by H. G. Schlegel \& B. Bowien. Madison, WI: Springer-Verlag, Berlin Science Tech Publishers.

Lahiri, C., Mandal, S., Ghosh, W., Dam, B. \& Roy, P. (2006). A novel gene cluster soxSRT is essential for the chemolithotrophic oxidation of thiosulfate and tetrathionate by Pseudaminobacter salicylatoxidans KCT001. Curr Microbiol 54, 267-273.

Meulenberg, R., Pronk, J. T., Hazeu, W., Bos, P. \& Kuenen, J. G. (1992). Oxidation of reduced sulfur compounds by intact cells of Thiobacillus acidophilus. Arch Microbiol 157, 161-168.

Miller, J. H. (1972). Experiments in Molecular Genetics, pp. 352-355, 403-404. Cold Spring Harbor, NY: Cold Spring Harbor Laboratory.

Miller, V. L. \& Mekalanos, J. J. (1988). A novel suicide vector and its use in construction of insertion mutations: osmoregulation of outer membrane proteins and virulence determinants in Vibrio cholerae requires toxR. J Bacteriol 170, 2575-2583.

Mukhopadhyaya, P. N., Deb, C., Lahiri, C. \& Roy, P. (2000). A soxA gene, encoding a diheme cytochrome $c$, and a sox locus, essential for sulfur oxidation in a new sulfur lithotrophic bacterium. $J$ Bacteriol 182, 4278-4287.

Randell, J. C. \& Coen, D. M. (2004). The herpes simplex virus processivity factor, UL42, binds DNA as a monomer. J Mol Biol 335, 409-413.

Rother, D., Henrich, H. J., Quentmeier, A., Bardischewsky, F. \& Friedrich, C. G. (2001). Novel genes of the sox gene cluster, mutagenesis of the flavoprotein SoxF, and evidence for a general sulfur-oxidizing system in Paracoccus pantotrophus GB17. J Bacteriol 183, 4499-4508. 
Rother, D., Orawski, G., Bardischewsky, F. \& Friedrich, C. G. (2005). SoxRS-mediated regulation of chemolithotrophic sulfur oxidation in Paracoccus pantotrophus. Microbiology 151, 1707-1716.

Sambrook, J. \& Russell, D. W. (2001). Molecular Cloning: a Laboratory Manual, 2nd edn. Cold Spring Harbor, NY: Cold Spring Harbor Laboratory.

Shore, D., Langowski, J. \& Baldwin, R. (1981). DNA flexibility studied by covalent closure of short fragments into circles. Proc Natl Acad Sci U S A 78, 4833-4837.
Skorupski, K. \& Taylor, R. K. (1996). Positive selection vectors for allelic exchange. Gene 169, 47-52.

Towbin, H., Staehelin, T. \& Gordon, J. (1979). Electrophoretic transfer of proteins from polyacrylamide gels to nitrocellulose sheets: procedure and some applications. Proc Natl Acad Sci U S A 76, 4350-4354.

Vishniac, W. \& Santer, M. (1957). The thiobacilli. Bacteriol Rev 21, 195-213.

Edited by: G. Muyzer 